\title{
Human Capital Development in the Age of Artificial Intelligence
}

\author{
Shahino Mah Abdullah*
}

\section{Industrial Revolution}

Improvement in standards of living can be attributed to emerging innovations and technological changes. Innovations in farming methods, for example, triggered the Agricultural Revolution in Britain, which then set off the Industrial Revolution in 1750 . Back then, the coal-powered steam engine significantly benefitted the iron industry, textile trade, and transportation. Since then, a series of innovations have emerged and successfully solved certain human inefficiencies and increased overall productivity. Although the British initially prohibited the export of technology and skilled workers, the Industrial Revolution nevertheless spread to other European countries and the United States.

The Second Industrial Revolution (2IR), known as The Age of Synergy, took place after 1850. The involvement of the United States, Germany and Japan saw more technological advancement in relation to electricity, radio communication, internal combustion engines, the petroleum industry, and mass production of automobiles, to name a few. In the Third Industrial Revolution (3IR), especially after 1960, manufacturing was increasingly digitised and automated. The Digital Revolution finally brought us to the era of advanced digital computers, internet networking, mobile communication, green electricity, robotic labour, and additive manufacturing. Today's technological advancement has led to the arrival of the Fourth Industrial Revolution (4IR), a new era of fusing the physical, biological, and digital worlds that will cover almost all disciplines.

Highlighted fields in the current industrial revolution are artificial intelligence (AI), big data, Internet-of-Things (IoT), blockchain technology, selfdriving vehicle, nanotechnology, renewable energy, quantum computing, and biotechnology. Before the year 2020, we will have witnessed AI developments unfold in real time and become significantly more important in our daily lives as tech consumers. Most young people think AI is a key part of their future. This is also supported by experts, who believe that AI automation in today's industry will completely transform the workplace. However, there are also concerns that it will affect the labour market if human capital is unable to cope with the new changes. 


\section{Impact of Industrialisation}

Many people around the world enjoy the benefits of industrialisation. However, rapid development has put individuals and social systems in a struggle to keep up. Although industrialisation has improved the standard of living for some, particularly the middle and upper classes, it has also compromised the living conditions of the poor and working classes. During the early age of industrialisation, there were serious issues concerning low wages, unhealthy working conditions, child labour, long working hours, increase in the risk of injuries, job insecurity for unskilled workers, craftspeople-to-machines replacement, overcrowded housing, unsanitary living conditions, and disease transmission. As a result, a group of English workers known as the Luddites arose against industrialisation and destroyed machines as an act of protest. Today, 'Luddite' has come to mean anyone opposed to industrialisation and new technologies.

But industrialisation affected not only them. Globally, industrialisation has had a great impact on all nations, especially present-day developing countries. Industrialisation in the contemporary developing world mainly traps low- or middle-income levels due to internal issues within specific countries, such as local monopolies and bad political institutions. Some of the developing nations also are not fully capable of following the rise of the previous 3IR and even struggle to cope with the 2IR. It is still uncertain how well they can prepare themselves and position their countries towards 4IR. Some of them are considered to have been left behind, and the situation is worsening, as industrialisation continues to evolve and show no signs of stopping.

From the writer's point of view, industrialisation must be sustainable in all aspects of human well-being, which includes promoting environmental protection. Both benefit and profit must be shared among the people, while the environmental ecosystem must be kept unharmed. When a new technology appears to facilitate everyday human life, replacing low-skilled labour with machines, more effort to educate and re-train the populace must follow suit. Therefore, the emergence of new technologies should also create new job scopes by empowering human capital, or at least matching the people to available jobs through necessary training.

At the local level, the Malaysian government's innovative efforts to minimise unemployment through the 1Malaysia Training Scheme (SL1M), for example, is more than just helping graduates to secure jobs. It is a platform to elevate and enhance human capital through collaboration with government-linked companies (GLCs) and private companies by providing necessary training to match graduates with jobs requirements. As the number of graduates increases every year, the number of jobs offered is expected to increase as well. This programme is one of the measures that must be continued every year in order to boost the quality of local human capital, especially in the midst of the 4IR era. 


\section{Synergising Human Capital and Al: An Islamic Perspective}

Human capital is integral towards achieving sustainable development. Human capital refers to individual productivity and capacity based on knowledge, skills, experience, and wisdom obtained through education and training. The most vital component in human capital is knowledge, as it lays the groundwork on which other aspects of human capital are built. The pursuit of knowledge is fundamental to the beliefs, conduct and practice of every Muslim. In the first revelation, God Most High asked us to read (iqra') to acquire knowledge. This is further supported by a hadith in which Abu al-Darda reported from the Prophet: "If anyone travels on a road in search of knowledge, Allah will cause him to travel on one of the roads to Paradise. The learned are the heirs of the prophets, and the prophets leave neither dinar nor dirham, leaving only knowledge, and he who takes it takes an abundant portion" (Abu Dawud, Book 19: Kitab Al-Ilm, No. 3634). The Prophet has also said in a well-known hadith that "pursuit of knowledge is an obligation of every Muslim." According to a variant report, the words "man and woman" are added to the end of this hadith.

Most Muslim scholars during the Islamic Golden Age of Science (c. 850$1250 \mathrm{CE}$ ) were knowledgeable polymaths who had vast understanding and expertise in many disciplines, e.g. science, mathematics, engineering, astronomy, and philosophy. One of the most prominent of such figures was Abu Ja'far Muhammad ibn Musa al-Khwarizmi, the founder and father of algebra, widely known for his contribution to the early problem-solving technique known as algorithm. Advances in algorithm in today's IT world have made it an effective method to perform calculation, data processing, and automated reasoning tasks. This, in turn, leads to the emergence of artificial intelligence (AI) which enables machines to perform formal reasoning and mimic human cognitive functions. At one stage, it gives the computer the ability to 'learn' from the input data without being explicitly programmed and allows it to optimise its own algorithm. This is known as Machine Learning, an AI programme that can adjust as well as alter itself.

However, many have opined that the increasing advancements in AI are a threat to the human race due to AI's capability to perform many complicated tasks far more efficiently. The exponential growth of AI has frightened some researchers, who are fearful of a possible AI apocalypse. To prepare for such a worst-case scenario, certain programmers have outlined a kill switch to stop AI from causing harm. Actually, AI should not be considered a new foe as it also has the potential to create new job scopes and empower human capital. However, a set of human capital initiatives and developments is necessary in order to adapt to these new technological advancements. 
Our time is one of accelerating change and we need to keep pace. The Qur'an (13:11) tells us that God will not change the condition of a people unless they change what is in themselves. In this case, we should focus on keeping up with emerging technologies, including AI, and strive to improve ourselves in order to gain an advantage. Some job scopes will continue to require a 'human touch' to ensure effectiveness, especially in jobs that entail communication, creativity, compassion, imagination, emotional intelligence, and critical thinking. We therefore need to emphasise developing higher-order thinking and emotional skills. Among other capabilities that people should consider are creative arts, sports, healthcare, education, politics and law. Finally, yet most importantly, we must address the challenges associated with regulating AI in order to manage the risks and maintain the well-being of human capital. As vicegerent of the Earth ( $k$ halifah) we must also take full responsibility for any consequences related to AI misconduct since its 'decision-making' process still remains under human control, having yet to achieve 'independent thought'. By being fully aware of the importance of enhanced human capital and the supportive role of AI, we should eventually create a sustainable working atmosphere while peacefully building the Earth in the true Islamic spirit of $i$ 'mar al-ard.

\section{Notes}

* Shahino Mah Abdullah is Research Fellow, International Institute of Advanced Islamic Studies (IAIS) Malaysia. 